\title{
Strut-and-tie models of masonry shear walls
}

\author{
Jasiński Radosław \\ Silesian University of Technology, Faculty of Civil Engineering, Building Structures Department, 44-100 \\ Gliwice, ul. Akademicka 5, Poland \\ e-mail: radoslaw.jasinski@polsl.pl
}

\begin{abstract}
This paper contains theoretical fundamentals of strut and tie models, used in unreinforced horizontal shear walls. Depending on support conditions and wall loading, we can distinguish models with discrete bars when point load is applied to the wall (type I model) or with continuous bars (type II model) when load is uniformly distributed at the wall boundary. The main part of this paper compares calculated results with the own tests on horizontal shear walls made of solid brick, silicate elements and autoclaved aerated concrete. The tests were performed in Poland. The model required some modifications due to specific load and static diagram.
\end{abstract}

Keywords: masonry shear walls; ST models; equilibrium models

\section{Introduction}

In this papers discusses the experimental verification of strut and tie models presented in the papers $[1,2]$. The concept of strut and tie models can be briefly described as replacing the real structure with the equivalent virtual system of bars representing the whole wall, and not only the single section as in case of typical panel models. Such an approach provides also relatively simple calculations of ultimate limit states without the need to make complex calculations. Such strut and tie models (models of bars in compression and bars in tension bars, strut and tie) are particularly used in reinforced concrete structures. However, they have not been commonly used in masonry structures probably due to their unrecognised experimental verification. The main aim of this paper, beside the obvious presentation of the method, is an attempt to modify assumptions of the original model.

\section{Short description of used models}

The author of discussed strut and tie models [1,

2] assumed the following:

1. Such models should be as simple as possible that is, the number of bars in compression and tension should be reduced to minimum.

2. Struts from that model characteristic for the compressed area can be defined as continuous or discreet. To represent point loads applied at a node, at least two struts should coincide.

3. Concentrated or uniform loads cause distribution of compressed areas in the wall in the form of parallelogram with to compression areas in the rectangular form with horizontal ties.

4. The maximum inclination of struts to the plane of head joints is limited by maximum shear stress in bed joints. Assuming the linear relation of Coulomb-Mohr for the description of maximum shear stresses, then the quotient of maximum and average compressive stresses in the wall are determined from tangent of maximum inclination of struts and ties as follows:

$$
\operatorname{tg} \phi=\frac{\tau_{R}}{\sigma_{y}}=\frac{f_{v 0}+\operatorname{tg} \alpha \sigma_{y}}{\sigma_{y}}=\operatorname{tg} \alpha+\frac{f_{v 0}}{\sigma_{y}}
$$

5. Inclination of ties depends on tensile strength of masonry in parallel or perpendicular direction to bed joints. As tensile strength in perpendicular direction to bed joints is close zero, ties are assumed to have only horizontal direction.

6. Tensile force in ties depends on inclination of struts coincided in nodes and should not exceed tensile resistance of ties. In practice, tensile strength of masonry in head joints is negligibly small. Therefore, tensile resistance depends on shear strength of masonry in planes of bed joints. The maximum tensile force $T$ in the tie is defined from the following condition:

$$
T \leq N_{i} \operatorname{tg} \phi
$$

where $N_{\mathrm{i}}$ is the minimum force in a strut coinciding in the node under consideration. Moreover, tensile force in the tie should not be greater than tensile strength of masonry units

$$
T \leq A_{b t} f_{b t},
$$

where: $A_{\mathrm{bt}}$ - cross sectional area of masonry units, $f_{\mathrm{bt}}$ - tensile strength of masonry units determined for perpendicular direction to the support area, 
7. For internal nodes of discrete type (CCT) composed of two struts and one tie to which tensile force $\mathrm{T}$ is applied, the following condition should be met

$$
T=N_{i}\left(\operatorname{tg} \beta_{1}-\operatorname{tg} \beta_{2}\right) \leq N_{i} \operatorname{tg} \phi,
$$

where $\beta_{1}$ and $\beta_{2}$ are inclinations of struts coincided in the considered node.

8. The minimal length of external node with the point load or support reaction, composed of one smeared strut (CCS) or two discrete struts (CCCS), is calculated using the equation:

$$
a \geq \frac{N}{t f_{c}},
$$

9. Shape and position of struts and ties should be adjusted to cracking effects and failure observed during the tests.

Taking into account the above assumptions, two types of strut-and-type models are used in practice [3]. They are models with discrete bars - type I model (Fig. 1a) and with smeared bars - type II model (Fig. 1b).

Shear resistance of type I models with discrete bars is expressed by the following equation:

$$
V_{I}=\min \left\{\begin{array}{l}
N \frac{b-d-m}{h} \\
\frac{2}{3} N \operatorname{tg} \phi \\
\frac{2 d N}{4 m} \operatorname{tg} \beta_{1}
\end{array} .\right.
$$

where: $N$ - total vertical load of the wall, $d-$ minimum distance between the area of external loading to vertical wall edge depending on eccentricity of the external load $(d=b / 2-e-$ $m / 2), b$ - wall length, $m=\frac{N}{t f_{c}}-$ minimum width to which external compression loads are transmitted assuming total yield load of the wall. $t-$ wall thickness, $x=b-d+m-$ distance between vertical resultant forces acting at the top and bottom wall edges, $f_{\mathrm{c}}-$ compressive strength of masonry.

Resistance of wall with smeared bars - type II model, is calculated from the following equation:

$$
V_{I I}=\min \left\{\begin{array}{c}
\operatorname{Ntg} \phi\left[1-\frac{h}{2 b} \operatorname{tg} \phi\left(\frac{1}{1-v}\right)\right] \operatorname{gdy} m \leq b-h \operatorname{tg} \phi \mathrm{i} x \leq b . \\
V \frac{b-m}{2 h} \operatorname{gdy} m>b-h \operatorname{tg} \phi
\end{array}\right.
$$
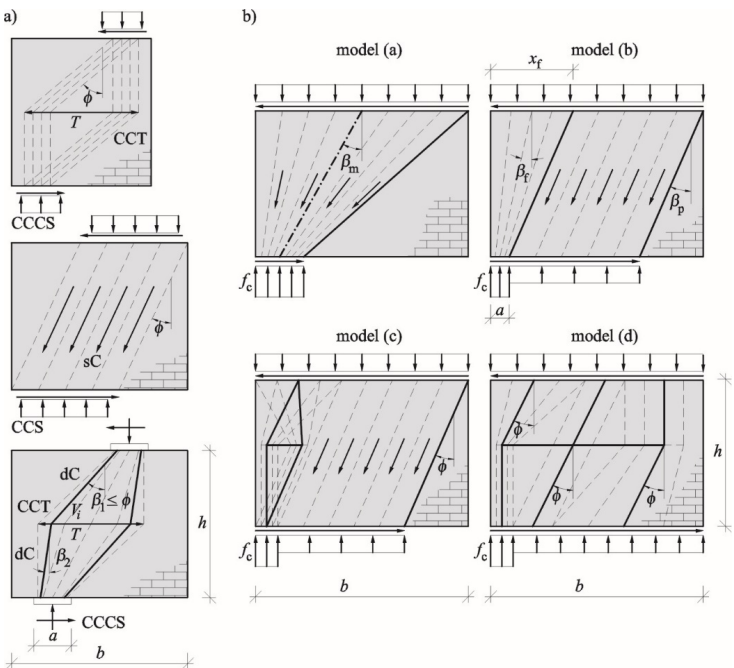

Figure 1. Strut-and-tie models of walls: a) models subjected to concentrated loads (type I models). b) models with uniformly distributed loading (type II models)

\section{Experimental model verification}

The proposed strut-and-tie models for wall strength were verified experimentally in different European research centres $[4,5,6,7]$. The calculations were compared to results obtained by testing five model series with different $h / b$ ratio and made of various masonry units on different mortar types, loaded and supported on cantilevers or partially fixed. The analyses confirmed the method usefulness for tested cantilever walls. The verification of strut and tie models, discussed in this paper, regarded fixed walls made of solid brick, silicate elements and autoclaved aerated concrete Fig. 2.

The sum of vertical reaction $R$ and the resultant of compressive prestress $\sigma_{\mathrm{c}}=\sigma_{\mathrm{y}}$ was assumed as the total wall vertical loading $N$.

The series of solid brick walls $[9,10]$ included walls with dimensions $b=1.68 \mathrm{~m}, h=1.42 \mathrm{~m}$ and thickness $t=0.25 \mathrm{~m}$ The tests involved 11 walls. Compressive strength of masonry, determined acc. to code PN-EN 1052-1:2000 Methods of tests for masonry. Part 1: Determination of Compressive Strenght was equal to $f_{\mathrm{c}}=8.99 \mathrm{~N} / \mathrm{mm}^{2}$, and shear parameters determined acc. to code PN-EN 10523:2004 Methods of tests for masonry. Part 3: Determination of Initial Shear Strenght were equal to $f_{\mathrm{vo}}=0.452 \mathrm{~N} / \mathrm{mm}^{2}, \operatorname{tg} \alpha=1.06$. The walls were tested at different values of compressive prestress of $\sigma_{\mathrm{c}}=0.0 ; 0.5 ; 1.0$ and $1.5 \mathrm{~N} / \mathrm{mm}^{2}$. Fig. 3 illustrates the comparison of test results (values of destructive forces were averaged for each $\sigma_{\mathrm{c}}$ value) and calculations using strut and tie models. 


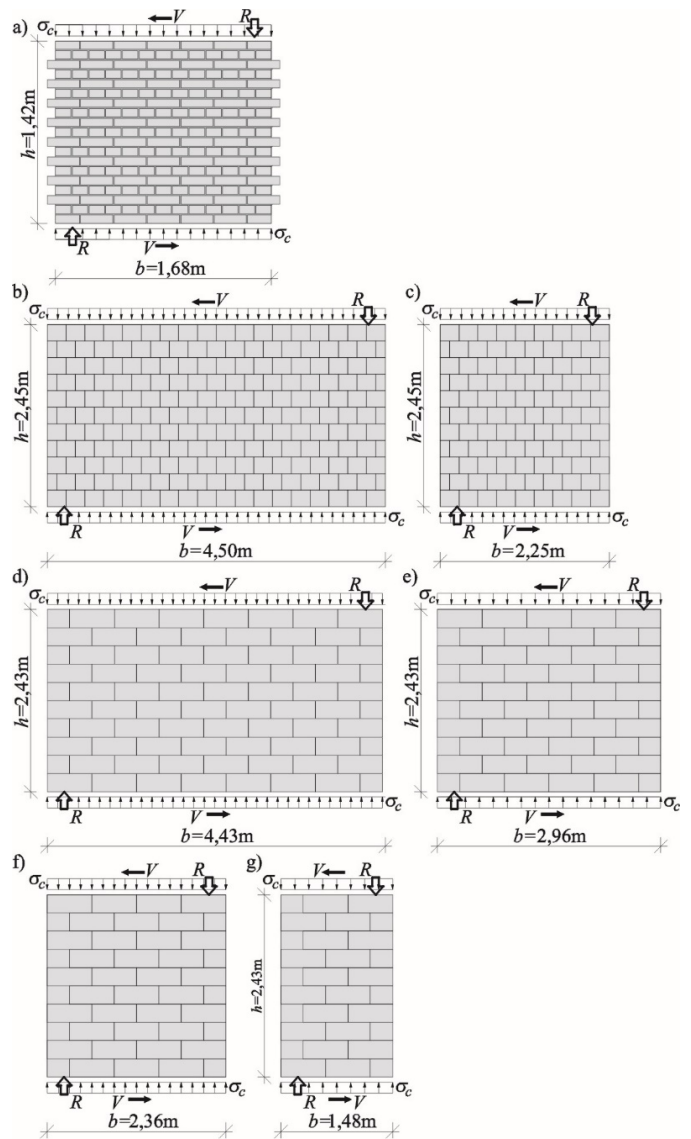

Figure 2. The original test models by Jasiński, used to verify strut-and-tie models: a) solid brick walls $[9,10]$, b), c) walls with silicate units [8], d), e), f), g) autoclaved aerated concrete [8]

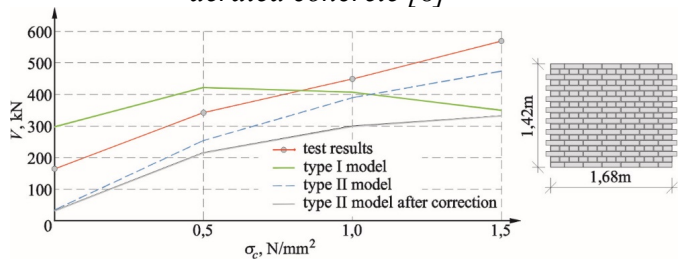

Figure 3. Compared results from tests and calculations for brick walls $[9,10]$

For type I model with discrete struts and ties at values of compressive prestress within the range of $0-0.8 \mathrm{~N} / \mathrm{mm}^{2}$, resistance was clearly overestimated. Results that are more favourable were obtained for model type II with smeared struts. Then, tested resistance values were significantly lower than calculated values within the whole range of compressive strength.

Two series of silicate units were tested. Their $h / b$ ratio was diversified. Tests on the basic series included three walls with the length $b=4.5 \mathrm{~m}$, the height $h=2.45 \mathrm{~m}$ and the thickness $t=0.18 \mathrm{~m}$. The walls were tested at different values of compressive prestress of $\sigma_{\mathrm{c}}=0.0 ; 0.1$ and $1.5 \mathrm{~N} / \mathrm{mm}^{2}$. The additional series of three units having the same height $h=2.45 \mathrm{~m}$ and thickness $t=0.18 \mathrm{~m}$ and reduced length $b=2.25 \mathrm{~m}$ was tested at compressive prestress values of $\sigma_{\mathrm{c}}=0.1 ; 0.75$ and $1.5 \mathrm{~N} / \mathrm{mm}^{2}$. Compressive strength of masonry, determined acc.to instructions from PN-EN 1052$1: 2000$ was equal to $f_{\mathrm{c}}=11.29 \mathrm{~N} / \mathrm{mm}^{2}$, and shear parameters determined acc. to instructions from PN-EN 1052-3:2004 were equal to $f_{\text {vo }}=0.70$ $\mathrm{N} / \mathrm{mm}^{2}, \operatorname{tg} \alpha=0.70$. Compared results from tests and calculations are shown in Fig. 4.

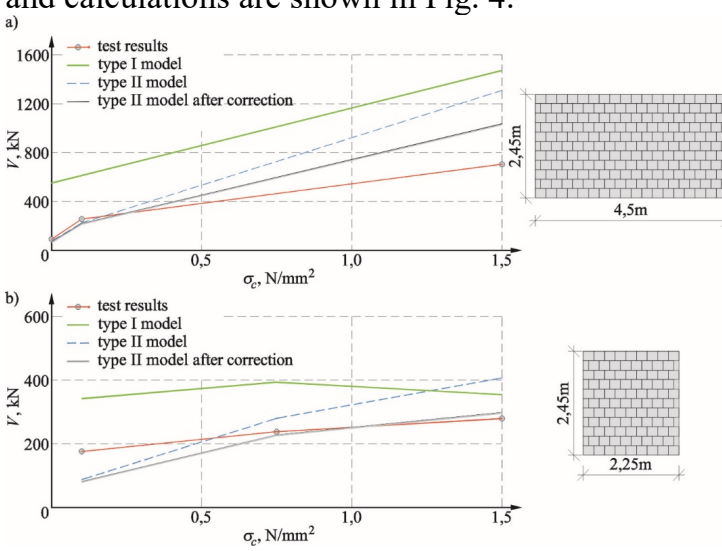

Figure 4. Compared results from tests and calculations for silicate units [8]: a) wall length $b=4.5 \mathrm{~m}, b$ ) wall length $b=2.25 \mathrm{~m}$

In that case, regardless of the ratio of height to length $h / b$, values of destructive forces obtained in the tests were much smaller than the ones calculated for models type I and II. The calculated resistance values were similar to empirical values depending on compressive prestress $\sigma_{\mathrm{c}}$. In contrast to brick walls, more squat walls with $h / b=0.54$ and increasing compressive prestress values, the calculated limiting forces were increasing acc., to model I, and decreasing in case of slender walls with the ratio $h / b=1.09$.

Considering AAC walls four series of units were tested. Their $h / b$ ratio was diversified. The basic series included walls with the length $b=4.43$ $\mathrm{m}$. Walls in other series were $b=2.95 \mathrm{~m}, 2.36 \mathrm{~m}$ and $1.48 \mathrm{~m}$ respectively. All walls had the same height $h=2.43 \mathrm{~m}$, and thickness $t=0.18 \mathrm{~m}$. Three walls in each series were tested at different values of compressive prestress of $\sigma_{\mathrm{c}}=0.0 ; 0.1$ and 1.5 $\mathrm{N} / \mathrm{mm}^{2}$. Compressive strength of masonry, determined acc. to instructions from PN-EN 1052$1: 2000$ was equal to $f_{\mathrm{c}}=2.97 \mathrm{~N} / \mathrm{mm}^{2}$, and shear parameters determined acc. to instructions from PN-EN 1052-3:2004 were equal to $f_{\mathrm{vo}}=0.3 \mathrm{~N} / \mathrm{mm}^{2}$, $\operatorname{tg} \alpha=0.62$. Compared results from tests and calculations are shown in Fig. 5. 


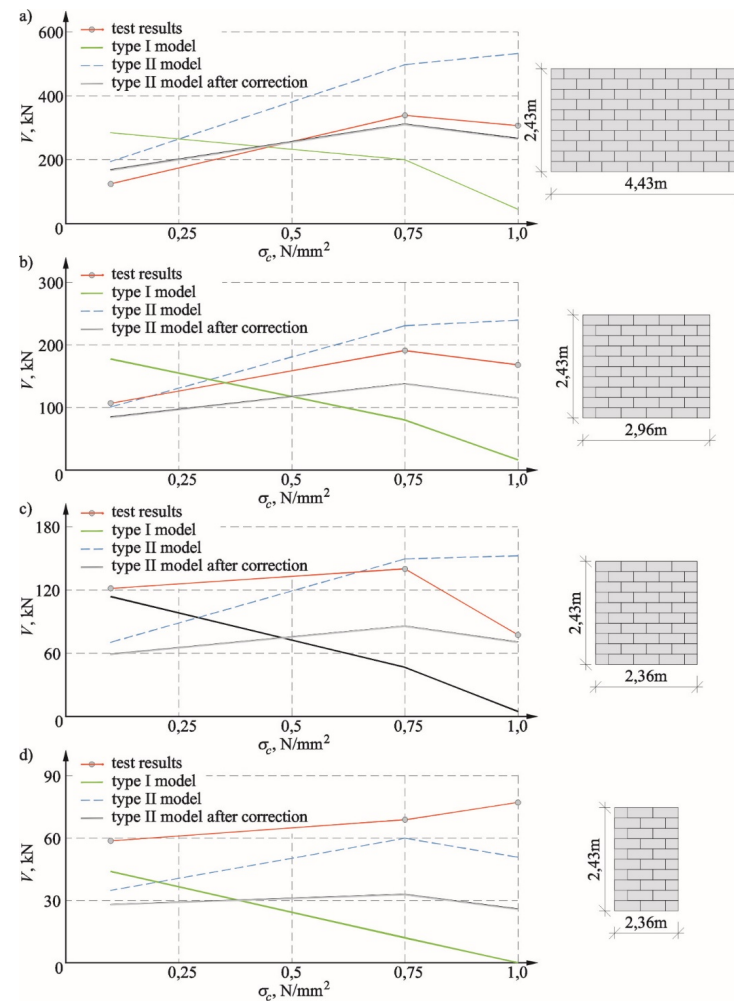

Figure 5. Compared results from tests and calculations for AAC walls [8]: a) wall length $b=4.43 \mathrm{~m}, b$ ) wall length $b=2.95 \mathrm{~m}, \mathrm{c}$ ) wall length $b=2.36 \mathrm{~m}, \mathrm{~d}$ ) wall length $b=1.48 \mathrm{~m}$

In type I models, squat walls with $h / b=0.55$ and $h / b=0.82$ and at the lowest values of compressive prestress, the calculated limiting forces were greater than experimental values. Walls compressed to the value of $0.75 \mathrm{~N} / \mathrm{mm}^{2}$ and 1.0 $\mathrm{N} / \mathrm{mm}^{2}$, the calculated values were considerably lower compared to experimental ones. Thus, the calculated values were greater than the empirical ones for type II model with smeared struts in the whole range of compressive stress values. Increasing slenderness of walls changed trends in the test results. For walls with $h / b=1.03$, the calculated resistance values for the model with discrete struts were lower than the ones determined in the tests. In case of the model with smeared struts, lower resistance was determined for the walls with the lowest compression load. The best results were obtained for the slenderest walls with $h / b=1.65$. Every time resistance values determined for models I and II were lower than the maximum resistance obtained in the tests.

In the studies conducted by the author, walls with the broader range of slenderness $h / b=0.50$ 1.85 and compressive resistance $f_{\mathrm{c}}=2.97-11.29$ $\mathrm{N} / \mathrm{mm}^{2}$ were verified. They were fully fixed (with bending moment at top and bottom wall edges). The calculated forces were lower than values determined in the tests. It is worth mentioning that only type II models with smeared struts reflected a trend observed in the tests. It suggested that the values of destructive force were greater as compressive prestress values were increasing. In type I models, the trend was just reverse and the lowest resistance of strut-and-tie model was obtained at the greatest vertical load.

According to the method assumptions, the best results were obtained when bars of the virtual strutand-tie model could be clearly determined in the direction of force streams. In the discussed tests, both concentrated force $R$ and uniformly distributed loading $\sigma_{\mathrm{c}}$ acted as external load. Therefore, discrete and smeared bars, that is type I and type II models, can be used in the walls. Contribution of particular models to loads mainly depended on the wall length $b$, in principle on the wall shape expressed by its slenderness $h / b$. Fig. 6a illustrates the obtained values of force $V$ in comparison to test results $V_{\text {obs }}$ against slenderness $h / b$.

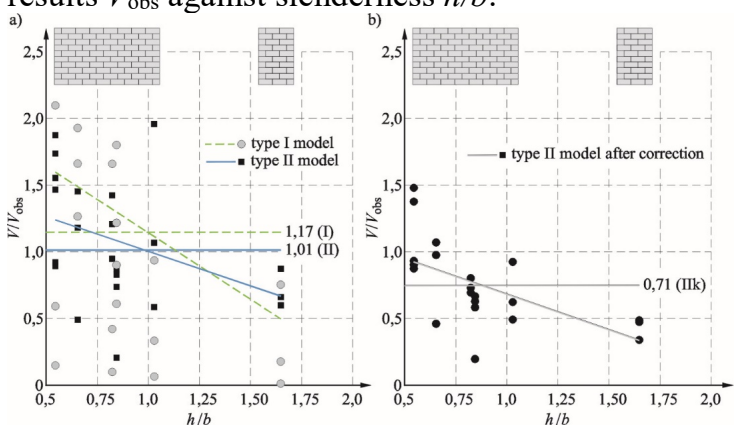

Figure 6. Compared tests results and own calculations: a) $V / V_{\text {obs }}$ relationships for type I and II models - wall slenderness $h / b$, b) $V / V_{\text {obs }}$ relationships for type II model after correction-wall slenderness $h / b$

Both in case of type I and II models, the results for squat walls with $h / b=0.5-0.8$ were ambiguous. It meant that the calculated force values were greater and lower than destructive forces observed in the tests. However, at increasing slenderness $h / b>0.8$, the calculated force values were lower than the experimental ones. Using type II model with smeared struts provided better convergence with the test results. Force values for type I models were used to estimate resistance with the excessive margin of safety.

The ratios $V / V_{\text {obs }}$ were clearly lower with increasing slenderness of walls $h / b$, both in case of type I and II models. As mentioned above, that situation was possible due to the presence of discrete struts in slender walls, and smeared, and even smeared and discrete struts in squat walls.

Two important factors were neglected in the proposed strut-and-tie models. Their impact was not observed in the verification tests. The first 
factor was related to determination of strut inclination to the plane of head joints expressed by the equation (1), which depended on limiting shear stress $\tau_{\mathrm{R}}$. Code PN-EN 1996-1-1:2010 Eurocode 6: Design of Masonry Structures. Part 1-1. General rules for reinforced and unreinforced masonry structures clearly recommends reducing initial shear strength of the masonry with head joints unfilled by $50 \%$. The corrected value $\operatorname{tg} \phi_{k o r}$ used in equations for resistance (6) and (7) should be as follows:

$$
\operatorname{tg} \phi_{k o r}=\frac{\tau_{R}}{\sigma_{y}}=\frac{0,5 f_{v 0}+\operatorname{tg} \alpha \sigma_{c}}{\sigma_{y}}=\operatorname{tg} \alpha+\frac{0,5 f_{v 0}}{\sigma_{y}} .
$$

The second important, but neglected factor was compressive strength of struts. Cracking caused by horizontal tensile stresses (induced by compression and shearing) resulted in reduced compressive strength. That problem is not identified in masonry structures, but occurs in reinforced concrete structures. Code PN-EN 1992-1-1:2008 Eurocode 2. Design of concrete structures. Part 1-1. General rules and rules for buildings introduces the so called reduced calculated stress reduced in struts obtained from the following equation:

$$
\sigma_{R d \max }=0,6 v^{\prime} f_{c d}=0,6\left(1-\frac{f_{c k}}{250}\right) f_{c d}
$$

This is the empirical expression which determines the damage level of concrete caused by tensile stresses. It is the function of compressive strength. The masonry structures have compressive strength $f_{\mathrm{c}}$ is much lower than concrete one. Thus, the value of bracketed expression is close to one $\left(f_{\mathrm{c}} / 250 \ll 0\right)$. Therefore, avoiding a serious mistake, reduced compressive stress in struts can be calculated from the following expression:

$$
\sigma_{c \max }=0,6 f_{c} .
$$

By substituting $\operatorname{tg} \phi \rightarrow \operatorname{tg} \phi_{k o r}$ and $f_{c} \rightarrow \sigma_{c \max }$ in the equation (7), the resistance of wall acc. to type II model after correction was calculated and presented in Figs 4-6. The comparison of all results in the form of $V / V_{\text {obs }}$ in the function of slenderness $h / b$ is illustrated in Fig. $7 b$.

The corrected parameters of the masonry in type II model with smeared struts provided greater convergence between calculated and test results. The average ratio of calculated resistance to the tested on was $V / V_{\text {obs }}=0.74$ and was over $25 \%$ lower than the value obtained for type II model without corrections. The results for squat walls seemed to be particularly encouraging as the average values of calculated forces were lower by $20 \%$ than the empirical values. In slender walls, such as interopenning pillars, the strut-and-tie model with smeared struts after corrections determined unreasonably reduced resistance. Generally, using strut-and-tie model composed of discrete and smeared struts seems to be appropriate. That mixed type III model, shown in Fig. 7 can be used to define resistance using the following expression:

$$
V_{I I I}=\alpha V_{I}+V_{I I}
$$

where:

$\alpha$ - empirical factor depending on the ratio of wall dimensions $h / b$ expressing the percentage resistance calculated acc. to rules defined for type I model.

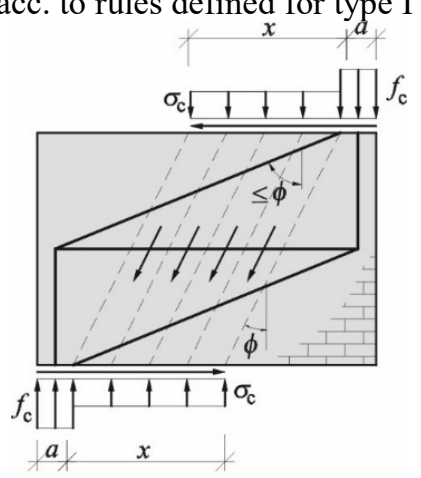

Figure 7. Concept of mix model - type III model

Discrete struts in type III model could be assumed to contribute to concentrated loads from the section having length $a$, at which compressive stresses reached compressive strength. And smeared struts will take the loads from the section with $x$ length, at which compressive stresses $\sigma_{\mathrm{c}}$ did not exceed $\sigma_{\text {cmax }}$ value. The test results for slender walls $(h / b>1)$ indicated that the contribution of forces from type I model could be neglected, that is, it could be assumed that $\alpha=0$. For squat walls the factor should be $\alpha>1$. Based on the own tests conducted on AAC walls with slenderness ratio $h / b$ $=1.65$, the determined factor was $\alpha=2.07$.

Estimating $\alpha$ factor was impossible due to relatively reduced materials, especially for slender walls. Walls made of different materials, with loaded cantilevers or partially fixed should be subjected to tests. 


\section{Conclusions}

The empirical verification of strut-and-tie models on wall models with cantilevers or partially fixed, performed in foreign research centres, produced successfully converge results. However, using the model with discrete or smeared struts, or partially cracked residual model not always produced results convergent with the test results. The reason was the complex strength parameters of masonry and working conditions of walls. On the other hand, the national tests provided less optimistic results for fixed walls. Moreover, they indicated the impact of slenderness as the results obtained from the models with discrete and smeared struts were clearly different from the case of slender walls. Some corrections to mechanical parameters were made to provide the satisfactory convergence between observations and calculations for squat walls. To sum it up, the present state of knowledge, particularly with reference to empirical verification, is not sufficient to unequivocally define rules applicable to individual models. Using the mixed type III model, composed of both discrete and smeared struts, seems to be the most reasonable. However, further analyses experimental verification of different types of walls are required to detail the rules of model building and estimate the potential unreliability of the obtained results.

\section{References}

[1] Roca P.: „Assessment of masonry shear-walls by simple equilibrium models". Construction and Building Materials. Vol. 20/2006, 229 238.

[2] Roca P., Lobato M., Viviescas Á., Villalba V.: "Limit analysis of shear walls by simple equilibrium models". $8^{\text {th }}$ International Masonry Conference 2010 in Dresden (CD ROM).

[3] Jasiński R.: „Simple equilibrium models of masonry shear walls - theoretical foundations". Materiaty Budowlane No 5/2016, $\quad 141 \quad-\quad 144 . \quad$ DOI: 10.15199/33.2016.05.61. (In Polish).

[4] Ganz H.R., Thürlimann B.: "Strength of brick walls under normal force and shear". Proceedings of the $8^{\text {th }}$ International Symposium on Load Bearing Brickwork, London 1983, $27-29$.

[5] Oliveira D.: "Mechanical characterization of stone and brick masonry". Rep. No. 00DEC/E-4, Univ. Do Minho, Guimaraes; 2000.

[6] Raijmakers T., Vermeltfoort A.: "Deformation controlled tests in masonry shear walls". Report B-92-1156, TNO-Bouw, Delft 1992.

[7] Vermelfoort A., Raijmakers T.: "Deformation controlled tests in masonry shear walls". Part 2. Report TUE/BKO/93.08, Eindhoven University of Technology, Eindhoven.

[8] Jasiński R.: „Research and modeling of masonry shear walls". PhD DsC Thesis. Silesian University of Technology, Gliwice, Poland 2017. (In Polish).

[9] Jasiński R.: „Strenght and deformability of reinforced clay brick masonry horyzonatally sheared". PhD Thesis. Silesian University of Technology, Gliwice, Poland 2005. DOI. 10.13140/RG.2.2.29271.68001. (In Polish).

[10] Jasiński R.: "Study of reinforced clay brick masonry walls horizontally sheared" $8^{\text {th }}$ International Masonry Conference, Dresden $2010,1231-1242$. 